\title{
De la substancia del diablo. Orígenes y la dinámica del sistema valentiniano de las tres naturalezas
}

\author{
Mariano Troiano \\ UNIVERSIDAD NACIONAL DE CUYO \\ mariantro@hotmail.com
}

Resumen: En el Tratado de los Principios I, 8, 2 Orígenes refuta explícitamente la doctrina de la existencia de tres naturalezas ( que él atribuye a los valentinianos. La doctrina de las diferencias naturales entre los hombres, provenientes de la acción de diversos creadores y determinantes de su destino final, es una de las afirmaciones más fuertemente instaladas por los adversarios de los autores gnósticos. Dichas afirmaciones han implicado una de las críticas más recurrentes hacia los textos gnósticos; críticas que incluso perduran entre los estudiosos actuales. Así, el objetivo final de nuestro trabajo es demostrar que la antropología valentiniana de las tres naturalezas no implica una doctrina determinista y estática, sino un sistema dinámico, donde el individuo, y no solo la humanidad, se encuentra tensionado entre sus tres naturalezas y donde incluso el elemento espiritual es impelido a buscar la salvación.

Palabras clave: Gnosticismo, Demiurgo, Naturaleza humana, Orígenes, Tratado Tripartito, Valentinismo.

Abstract: In Origen's On First Principles I, 8, 2, the Alexandrian explicitly refutes the doctrine of the existence of three human natures ( $\varphi v$ oı) which he attributes to the Valentinians. The doctrine of the natural differences between men, due to the action of various creators and decisive on their final destination, is one of the claims most heavily installed by the opponents to the Gnostic authors. Such claims have involved one of the most recurring critics to the Gnostic texts; critics that persist even among modern scholars. Thus, the ultimate goal of our work is to demonstrate that the Valentinian anthropology of three natures does not imply a deterministic and static doctrine, but a dynamic system, where the individual, not only the humanity as category, is stressed between the three natures and where even the spiritual element is urged to seek salvation.

Keywords: Gnosticism, Demiurge, Human Nature, Origins, Tripartite Treaty, Valentinianism. 


\section{INTRODUCCIÓN}

En el Tratado de los Principios I, 8, 2 Orígenes refuta explícitamente la doctrina de la existencia de tres naturalezas humanas que él atribuye a los autores gnósticos valentinianos. La siguiente cita sintetiza su crítica a tales posturas:

"No hay entonces naturaleza incapaz de recibir el bien o el mal, si no es la de Dios, fuente de todos los bienes, y la de Cristo [...] Pero toda otra naturaleza que es santa [...] no la posee por naturaleza, sino de manera accidental, ahora bien, aquello que es accidental puede perderse" 1 .

Confirma tal afirmación lo expuesto en su Comentario sobre el Evangelio de Juan donde confronta al valentiniano Heracleón ${ }^{2}$ quien, nos transmite Orígenes, sostiene que las naturalezas que dividen a los hombres (material, psíquica y espiritual) son inmutables ${ }^{3}$.

De manera tal que la doctrina de las diferencias naturales entre los hombres, provenientes de la acción de diversos creadores y determinantes de su destino final, es una de las afirmaciones más fuertemente instaladas por los adversarios de los autores gnósticos y ha implicado una de las críticas más recurrentes hacia sus textos. Críticas que incluso perduran entre los estudiosos actuales, tal como lo expone y refuta Karen L. King ${ }^{4}$ analizando el ejemplo expuesto por el texto gnóstico del Libro

1 H. Crouzel - M. Simonetti (eds.), Orígenes, Peri Archôn I, 8, 3 (SC 252) (Paris 1978) 228-229.

2 Heracleón, nos informa Clemente de Alejandría, fue uno de los discípulos más

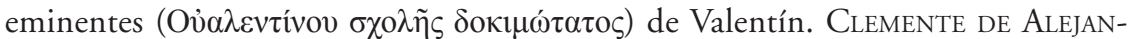
Dría, Stromata IV, 9, 71, 1, ed. A. Van den HoeK- trad. C. Mondésert (SC 463), Paris, 2001, 172-173. Ver también el capítulo 1 de la obra de T. J. Pettipiece, Heracleon: Fragments of early Valentinian exegesis. Text, translation, and commentary (2002). Theses and Dissertations (Comprehensive). Paper 130. Wilfrid Laurier University, 4-16.

3 Orígenes, In Jo. XIX, XIV, 90, ed. C. Blanc (SC 290) (Paris 1982) 102-103.

4 K. L. KING, What Is Gnosticism? (Cambridge, Mass. London 2003) 202-205 y 330, nota 39. La autora centra incluso su análisis en obras que se ocupan del supuesto determinismo valentiniano y expone los nuevos enfoques aportados a partir del estudio profundo de los textos descubiertos en Nag Hammadi. K. L. KinG, What Is ... 206-208. Afirma que los textos de Nag Hammadi no observan al cuerpo y al mundo como malvados per se, pero solo como el campo de batalla donde se libra la lucha entre el bien y el mal. "Nor does it regard the body and the world as evil per se, but only as the battleground on which the struggle between good and evil is waged». K. L. KING, What Is ... 200. 
De la substancia del diablo. Orígenes y la dinámica del sistema valentiniano... 609

de Tomás: "El Salvador ofrece claramente dos opciones e insiste en que la gente haga una elección. Uno es salvado no por naturaleza sino por seguir la luz y comprometerse con prácticas ascéticas" ${ }^{5}$.

En este marco, nuestra intención no es refutar las interpretaciones transmitidas por Orígenes, más aún siendo el Padre de la Iglesia fuente indispensable para abordar el pensamiento de Heracleón, importante discípulo de Valentín y redactor, hacia el tercer cuarto del siglo II, del primer comentario al Evangelio de Juan conocido hasta el momento ${ }^{6}$. Sin embargo, consideramos al igual que la autora mencionada, que el descubrimiento de los textos de Nag Hammadi permite el acceso a fuentes directas que aportan una nueva perspectiva sobre las ideas que los autores gnósticos presentan sobre la composición del hombre.

En este sentido, nuestro trabajo intentará confrontar las afirmaciones vertidas por Orígenes en su Comentario sobre el Evangelio de Juan, pero principalmente en el Tratado de los Principios, sobre la concepción gnóstica de las diferentes naturalezas humanas, con el análisis que sobre dicha concepción se puede realizar gracias a uno de los escritos valentinianos más notables como es el caso del Tratado Tripartito (NH I, 5). Asimismo, no desdeñaremos los aportes explicativos que sobre este tema expone la lectura de los Extractos de Teódoto.

5 «The Savior offers two clear alternatives and insists that people make a choice. One is saved not by nature but by following the light and engaging in ascetic practices». K. L. KING, What Is ... 196.

6 T. J. Pettipiece, Heracleon ..., 4. De todas maneras, sobre los fragmentos rescatados gracias a Orígenes, el autor nos previene que solo una cita (In Jo. XX, XX, 168) es introducida por las palabras: «El dice en sus propios términos» lo cual nos indica que las restantes no son citas textuales. Incluso el editor, Cécile Blanc afirma: «No siempre es fácil de ver dónde termina el texto de Heracleón y donde comienza el comentario de Orígenes» («Par ailleurs, il n'est pas toujours facile de voir où cesse le texte d'Héracléon et où commence le commentaire d'Origène»). Orígenes, In Jo, ed. C. Blanc (SC 120 bis), Paris (1966) 1996, 16. Ver también lo expuesto por Pettipiece sobre el estado fragmentario de la transmisión del comentario de Orígenes mismo en T. J. Pettipiece, Heracleon ..., 158-159. Sin embargo, es claro que para Orígenes Heracleón fuerza y mal interpreta intencionalmente los textos sagrados (In Jo. II, XIV, 100-101). Orígenes, por su parte, afirma la regla de fe: Cristo, hijo de Dios, siendo la verdadera transmisión de sus palabras a través de los apóstoles y conservadas por la Iglesia Peri Archôn I, 3 (SC 252), 79. En cuanto a la validez metodológica de los fragmentos ver Orígenes, Peri Archôn, 8-9. 
El objetivo final de nuestro trabajo, en sintonía con lo expuesto por Einar Thomassen en sus notas a la edición francesa de los textos de Nag Hammadi ${ }^{7}$, es demostrar que la antropología valentiniana de las tres naturalezas no implica una doctrina determinista y estática, sino un sistema dinámico, donde el individuo y no solo la humanidad se encuentra tensionado entre sus tres naturalezas y donde incluso el elemento espiritual debe buscar la salvación ${ }^{8}$.

\section{A. ORÍGENES Y LA CONCEPCIÓN VALENTINIANA DE LAS TRES NATURALEZAS}

Dentro de la antropología valentiniana contra la cual polemiza Orígenes, se destacan dos aspectos fundamentales. Por un lado, la división radical del género humano en individuos compuestos por alguna de las tres naturalezas: materiales o terrestres, psíquicos y espirituales. Por otro, el destino final inmutable de cada uno de estos grupos.

Como hemos expuesto, en el libro del Tratado de los Principios (I, 8, 2), Orígenes asocia la concepción de las naturalezas espirituales diferentes (naturas spiritales diuersas), tanto entre los seres humanos como entre los seres celestiales producto de creadores diferentes, a los pensadores valentinianos9. Así para estos existirían los hombres materiales o hílicos excluidos de toda vida espiritual y para los cuales la salvación no tiene ningún sentido; los psíquicos capaces de obtener una salvación de segundo orden; y los espirituales salvados por naturaleza.

Por su parte, Orígenes acepta la diferencia entre los seres pero la atribuye no a creaciones disímiles sino a la fidelidad de sus movimientos con respecto a su origen divino ${ }^{10}$. Este busca refutar dicha interpretación

\footnotetext{
E. Thomassen - L. Painchaud, “Traité Tripartite” en EcrGnos (175-176, nota 105) 29-32.

8 Existen, por supuesto, otras corrientes gnósticas (los llamados "textos setianos" o la gnosis basilidiana) que presentan diferencias doctrinales con respecto a la concepción valentiniana del hombre. Sin embargo, dado el tiempo destinado a nuestra comunicación centraremos nuestro análisis en la ya de por sí compleja concepción valentiniana.

9 Orígenes, Peri Archôn (SC 252), 223. Ver también Origènes, In Jo. (SC 120 bis), 15.

10 Orígenes, Peri Archôn I, 8, 2 (SC 252), 225. Orígenes reprocha a los valentinianos el considerar a Pablo y a Pedro como espirituales siendo que en las escrituras son evidentes sus faltas. La postura del alejandrino argumenta contra los gnósticos quienes indican que tanto Pablo como Pedro estarían habitados por otro ser. Orígenes, Peri Archôn, 225.
} 
De la substancia del diablo. Orígenes y la dinámica del sistema valentiniano... |611

defendiendo al mismo tiempo la existencia de un creador único, justo y bueno, y la libertad del hombre, responsable ante Dios de sus actos ${ }^{11}$.

En el Comentario sobre el Evangelio de Juan nos informa sobre la inmutabilidad de las distintas naturalezas humanas expuestas por Heracleón ${ }^{12}$. Esta inmutabilidad es debida, en el caso de los materiales, a que comparten la naturaleza más corrompida del demiurgo, la materia. El discípulo de Valentín imputa a los judíos que acusan y no aceptan las palabras de Jesús (Jn 8, 43-44) el poseer dicha naturaleza. Orígenes nos dice:

"Pero ahora él (i. e. Heracleón) afirma, es evidente, que ciertos hom-

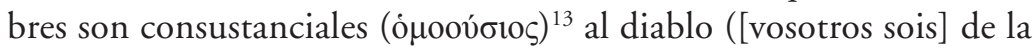

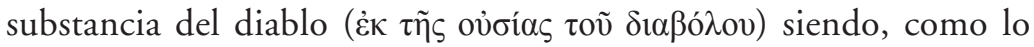
piensan sus discípulos, de una substancia (ov̉oía) diferente de aquellos

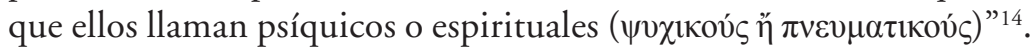

Un poco más adelante Orígenes aclara que los materiales serían para Heracleón hijos por naturaleza ( ұӧ̈кои́s) del Diablo, mientras que los psíquicos habrían devenido hijos del diablo por adopción: "Él dice que es porque ellos han amado los deseos ( $\dot{\varepsilon} \pi \imath v \mu$ í́ $\alpha)$ del diablo y que los llevan a cabo, que estos devienen criaturas del diablo, aunque no lo son por naturaleza (

Orígenes rechaza tal idea de una generación diferenciada entre los seres que integran el cosmos y manifiesta que toda creación proviene de un mismo creador ${ }^{16}$. Así, Dios ha creado en un comienzo todas las almas

11 Orígenes, In Jo. (SC 120 bis), 26.

12 Orígenes, In Jo., XIX, XIV, 90, ed. C. Blanc (SC 290) (Paris 1982) 102-103.

13 Sobre la concepción origeniana de la consubstanciación ver Orígenes, In Jo. (SC 290), 233, nota 4.

14 Orígenes, In Jo., XX, XX, 168-169 (SC 290), 240-241. En este sentido es interesante comparar con lo expuesto en In Jo. XX, XXVIII, 252-253 (SC 290), 280-283.

15 Orígenes, In Jo., XX, XXIV, 213-214 (SC 290), 262-263. Cf. J. D. Dubois, "La Sotériologie valentinienne du Traité Tripartite” (NH I, 5), en L. PaInchaud - A. PASQUiER (dir.) Les textes de Nag Hammadi et le problème de leur classification, eds. (Québec-Louvain-Paris, 1995) 226. Es interesante remarcar que Heracleón parece utilizar indistintamente el concepto "naturaleza" (

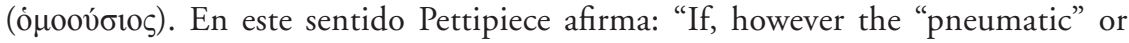
"spiritual" individual ( $\pi v \varepsilon v \mu \alpha \tau$ cós) is capable of passing from a state of darkness

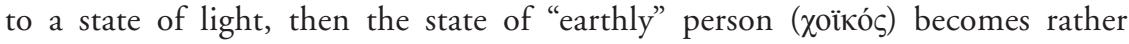
ambiguous in any theory of natures" T. J. Pettipiece, Heracleon ..., 40.

16 «Dios bueno y Padre benévolo del universo y la potencia bienhechora y demiúrgica, es decir aquella de hacer el bien, de crear y de proveer». Orígenes, Peri Archôn I, 4, 3 (SC 252), 169. 
similares, igualmente dotadas de libertad y las invita a seguirlo. Pero mientras que unas eligen por decisión propia la imitación de su creador y progresan; otras caen en la negligencia. Es según el mérito de cada una que Dios organiza un universo harmónico donde las reparte entre los diferentes seres ${ }^{17}$.

Sin embargo, si la creación tiene un origen único, Orígenes reconoce tres categorías de seres: celestes, terrestres e infernales, para los cuales la bondad no es substancial sino accidental y quienes poseen la libertad de permanecer o alejarse de ese origen divino inicial empujados por los movimientos de su inteligencia y su voluntad ${ }^{18}$. Tal es la caída, el apartarse del estado beatífico inicial, donde el orden de los seres celestes es el más próximo al origen y el que instruye sobre el camino de retorno. El género humano compone un orden apartado pero no de manera irremediable. El último orden lo componen el Diablo y sus secuaces, indignos de la formación aportada por los seres celestiales; son adversarios de los hombres y buscan alejarlos de las enseñanzas salvadoras ${ }^{19}$.

En el Comentario, el alejandrino insiste que la substancia que com-

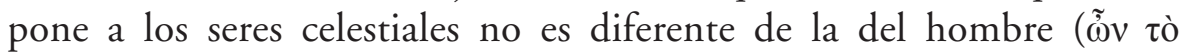

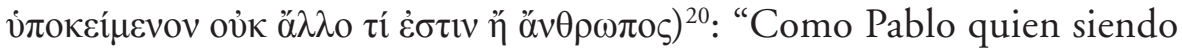
tinieblas, es capaz de devenir luz en el Señor (Ef. 5, 8), así aquel que sea tinieblas en cualquier momento (puede devenir luz) [...] es posible entonces que las tinieblas cambien en luz" ${ }^{21}$.

Así es, según su malicia, que ciertas almas caídas devienen demoníacas y otras humanas. El alma, en su preexistencia absolutamente espiritual, estaba unida plenamente a Dios y a su Palabra antes de su descenso ${ }^{22}$.

17 Y hace de ellas «vasijas de oro, de plata, de madera o de arcilla, unas para un uso honorable, otras para un uso despreciable, utilizando estas diversas vasijas que son las almas o las inteligencias». Orígenes, Peri Archôn II, 9, 6, eds. H. Crouzel y M. SimonetTi (SC 253), París, 1978, 366-367.

18 Orígenes, Peri Archôn I, 6, 2 (SC 252), 199

19 Orígenes, Peri Archôn I, 6, 3 (SC 252), 201-203.

20 Orígenes, In Jo., II, XXIII, 144 (SC 120 bis), 308-309.

21 Orígenes, In Jo., II, XX, 134-136 (SC 120 bis), 300-301. En el libro XX, se mencionan las semillas que las almas traen con ellas, sean semillas justas o injustas: «Sin embargo, no hemos venido todos al mundo con semillas parecidas e idénticas, pero ninguno ha venido desprovisto de semillas salvadoras y santas [...]». In Jo XX, V, 38 (SC 290), 174-175.

22 In Jo XX, XIX, 162. 
De la substancia del diablo. Orígenes y la dinámica del sistema valentiniano... |613

Estas afirmaciones del Comentario plantean dos puntos fundamentales: primero, las almas comienzan la adquisición de semillas justas o injustas antes de su encarnación y es según su mérito que el Creador les designa su función entre la jerarquía de los seres. Tal interpretación nos conduce a un segundo elemento central en la polémica con los autores valentinianos: la polémica sobre la salvación de las almas.

Es concluyente para Orígenes, que Dios ha creado a todos los seres racionales con una misma substancia, la substancia razonable ${ }^{23}$ «y son las causas antecedentes (i.e. a la encarnación) que han destinado unas al honor y otras al deshonor ${ }^{24}$. Y él afirma:

"[Contra] aquellos que inventan la doctrina de las naturalezas ( $\varphi v ́ \sigma \varepsilon ı \varsigma) ~[. .$.$] de una sola pasta provienen los perdidos y los salvados,$

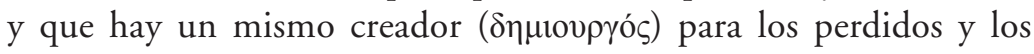
salvados, si es bueno aquel que hace no solamente a los espirituales

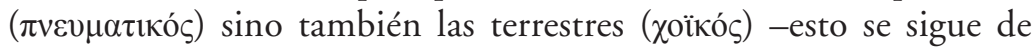
aquello- es posible seguramente que aquel que es ahora una vasija de honor $[\ldots]$ sea (si no actúa luego de la unión con el cuerpo conforme a su dignidad de vasija de honor) en otro siglo una vasija de deshonor y viceversa" 25 .

En el pensamiento origeniano toda naturaleza es susceptible de recibir tanto el bien como el mal y todo ser, gracias a su libre albedrío, adhiere ya sea al bien ya sea al mal (Peri Archôn I, 8, 3). Es Dios quien designa el lugar de cada alma según su progreso. Así, la función de los seres celestiales les viene según sus méritos y los demonios, obtienen sus grados en la maldad, según sus progresos en el crimen. De tal manera

23 En este sentido el alma es (voũc) es decir, principio de la vida racional y principio vital del cuerpo.

24 Orígenes, Peri Archôn III, 1, 22, eds. H. Crouzel y M. Simonetti (SC 268), París, 1980, 138-139

25 Orígenes, Peri Archôn III, 1, 23 (SC 268), 142-143. Todas las almas, dice Orígenes, santas o malvadas, han sido creadas y son de naturaleza incorpórea. OríGENES, Peri Archôn I, 7, 1 (SC 252), 209. Henri Crouzel y Manlio Simonetti interpretan que para Orígenes si bien toda alma es incorpórea en sí misma, ella está siempre revestida de un cuerpo, burdo en el caso de los hombres y etéreo en el caso de los ángeles, los resucitados y los demonios (Cf. Peri Archôn I, pref. 8). Orígenes, Peri Archôn (SC 252), nota 4, 105. En esta afirmación de un solo creador, Henri Crouzel y Manlio Simonetti ven una afirmación antignóstica ya que para los valentinianos la esencia espiritual o pneumática no ha sido creada sino emanada. OríGENES, Peri Archôn (SC 252), nota 3, 105. 
que la ausencia de conversión no proviene de su naturaleza sino principalmente de su voluntad que se delecta con el $\mathrm{mal}^{26}$. El género humano, por su parte, progresa hasta el orden celeste o se precipita ${ }^{27}$.

El concepto del libre albedrío ( $\tau$ ò $\alpha$ $\tau \varepsilon \xi o v ́ \sigma ı v)$ es clave en el sistema salvífico del alejandrino. Los diferentes grados de naturalezas provienen justamente de la facultad del libre albedrío otorgada a los seres racionales y su voluntad de progresar hacia la imitación divina o de caer como consecuencia de su abandono ${ }^{28}$. De esta libertad de los seres racionales, como hemos dicho, se deriva la diversidad del universo ${ }^{29}$. Orígenes polemiza entonces con aquellos que suprimen "[...] el libre albedrío sosteniendo que hay naturalezas perdidas incapaces de salvación y otras salvadas que son incapaces de perderse $[\ldots]^{\prime 30}$.

En el libro III $(1,3)$ del Tratado, Orígenes define el libre albedrío centrando sus argumentos en los seres dotados de razón $(\lambda o ́ \text { os })^{31}$. La razón, explica el alejandrino: "posee en su naturaleza los medios de ver el bien y el mal, que utilizamos para ver el bien y el mal y así elegir el bien o rechazar el mal [...]"32. Así, el hombre no se encuentra sometido a impulsos exteriores sino a una elección de la razón para examinar la influencia exterior ${ }^{33}$.

26 Orígenes, Peri Archôn I, 8, 4 (SC 252), 231.

27 Orígenes, Peri Archôn I, 8, 4 (SC 252), 231-233. Así, el universo tiene un origen único pero su diversidad proviene del alejamiento de los seres de la bondad inicial por sus agitaciones y deseos de sus intelectos. Orígenes, Peri Archôn II, 1, 1 (SC 252), 236-237.

28 Orígenes, Peri Archôn II, 9, 6 (SC 252), 364-365.

29 Orígenes, Peri Archôn II 9, 6 (SC 252), 366-367 (Cf. Con la Degradación de la inteligencia del alma en Peri Archôn II, 8, 3-4 y 9, 2)

30 Orígenes, Peri Archôn III, 1, 8 (SC 268), 48-49. Negar el libre albedrío, afirma Orígenes, tal cual lo hacen los seguidores de «Marción, Valentín y Basílides» para quienes las diferencias existentes en el universo no se condicen con un único creador sino con diferencias originarias esenciales, es aceptar que todo es regido de antemano por el azar. De aceptar esta solución no solo el mundo no ha sido hecho por Dios, sino que no está regido por la providencia y por ende no se puede esperar el juicio divino. Orígenes, Peri Archôn II, 9, 5 (SC 252), 361-365.

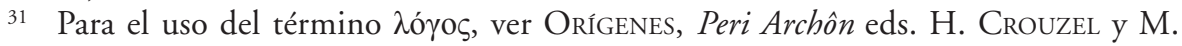
SimonetTi (SC 269), París, 1980, nota 12, 19.

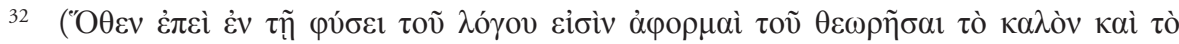

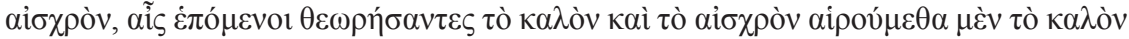

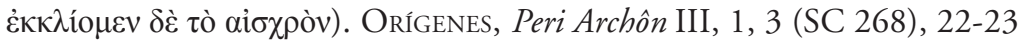

33 Orígenes, Peri Archôn III, 1, 5 (SC 268), 33. En el libre albedrío reside entonces la posibilidad de vencer las tentaciones: «Esta posibilidad que nos es dada de poder 
De la substancia del diablo. Orígenes y la dinámica del sistema valentiniano... 615

En el sistema origeniano la naturaleza divina está exenta de todo cambio y toda degradación y por ende, estar dotado exclusivamente de una naturaleza divina, como sería el caso de los espirituales dentro de la concepción gnóstica, implicaría la incapacidad de pecar por lo cual no haría falta la misericordia de $\operatorname{Dios}^{34}$. En un argumento equivalente, Orígenes incluso mantiene latente la respuesta sobre la posibilidad de la salvación de los seres infernales ${ }^{35}$.

En el libro IV del Tratado encontramos la concepción de Orígenes sobre el hombre "compuesto de un alma, un cuerpo y un espíritu de vida" ${ }^{36}$. Para el pensador alejandrino existe una sola alma disputada entre la carne y el espíritu ${ }^{37}$. Si hay una sola alma ella es a la vez principio de la vida racional y principio vital del cuerpo. La carne que desea contra el espíritu no es otra cosa que el alma atraída por las necesidades corporales de las cuales obtiene un placer malsano.

Así debemos entender la diferencia que Orígenes establece en su exégesis de Génesis 1, 26-27 entre "su imagen" (cf. Col. 1, 15) reservada en sentido estricto a Cristo, el Logos o incluso la Sabiduría, y "según la imagen" correspondiente al alma, al hombre interior ( y no al cuerpo, ni incluso a un compuesto de alma y cuerpo ${ }^{38}$. En una línea filoniana, Orígenes, pone el acento en el Verbo, "imagen” invisible "del Dios invisible" (Peri Archôn II, 6, 3 cf. Col. 1, 15) en su generación eterna, y en su rol de creador y revelador ${ }^{39}$. En consecuencia, aquel pri-

vencer, según la facultad del libre albedrío, o bien la empleamos con diligencia y vencemos o bien con pereza y somos derrotados» Orígenes, Peri Archôn III, 2, 3 (SC 268), 167.

34 Ver también Orígenes, In Jo XIII, 11, ed. C. Blanc (SC 222), París (1975) 2006, 67-74.

35 Orígenes, Peri Archôn I, 6, 3 (SC 252), 203. La salvación proviene de la instrucción de los seres celestes que permiten a cada alma de pasar de un orden al siguiente ya que "cada ser, a causa de la facultad del libre arbitrio, es susceptible de progreso o de decadencia, según sus movimientos y sus propios esfuerzos». Peri Archôn I, 6, 3 (SC 252), 205.

36 Orígenes, Peri Archôn III, 4, 1 (SC 268), 201. Ver también Peri Archôn (SC 269), nota 2,85 .

37 Orígenes, Peri Archôn III, 4, 4-5 (SC 268), 208-215.

38 M. Borret (éd.) Orígenes, Contra Celso VI, 63 (SC 147) (París, 1969) 334-339. Ver también C. Celso IV 83, VII, 66 y In Jo. , VI, XLIX, 252.

39 M. AleXandre, Le commencement du livre Genèse I-V (París, 1988) 243. 
vado del espíritu divino se vuelve terrestre (I Cor 15, 47) y es el espíritu quien da vida al alma ${ }^{40}$.

En el caso de las almas más degradadas, si bien todas han sido creadas por Dios con la misma substancia, cuando una se somete a las pasiones de la carne ella no percibe lo espiritual y es en este sentido que ella se «vuelve carne» (Cf. Rom 8, 7) ${ }^{41}$.

\section{B. TEXTOS GNÓSTICOS}

\section{El Tratado Tripartito (NH I, 5)}

Para poder entender la complejidad de la antropogonía valentiniana debemos abordar brevemente el relato exegético de la generación del hombre.

De acuerdo con el Tratado Tripartito, texto de ochenta y ocho páginas que data de principios del siglo III, atribuido a un autor cristiano de la escuela de Valentín, el mundo existe en función del hombre y gracias a la providencia de Dios, para fomentar el crecimiento espiritual del primero.

"Todo el edificio del la creación ( $\left.\tau c \_\in s \omega\right)$ imágenes, representaciones e imitaciones ha llegado a la existencia para aquellos que necesitan instrucción, enseñanza y formación, para que lo pequeño crezca

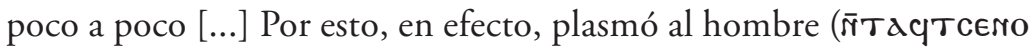
$\boldsymbol{\mu}$ пршеє) al final, habiendo previamente preparado y con anterioridad provisto para él lo que había creado por su causa” ${ }^{42}$.

El término utilizado para describir la creación Jca€sw (embellecer, adornar, ordenar) proviene del verbo catıє en el sentido de algo bello

40 Orígenes, In Jo., XIII, XXIV, 141-142 (SC 222) 106-109.

41 Orígenes, Peri Archôn III, 4, 5 (SC 268), 215. Descubrimos aquí una posible interpretación de un término gnóstico. En el texto la Pensée Première à la triple

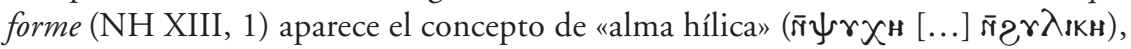
oxímoron que indica la condición mortal de las almas corrompidas. PrôTri 35, 18. P. H. Poirier, La Pensée première à la triple forme (BCNH 32), Québec-Louvain-Paris-Dudley, 2006, 132-133.

42 TrTrip 104, 18-30. F. GaRCía BAZÁN, “Tratado Tripartito NHC I 5”, Textos Gnósticos I (Madrid, 2000) 193. L. Painchaud - E. Thomassen, «Traité Tripartite», EcrGnos, 174. Aussi E. Thomassen, Le Traité Tripartite (BCNH 19), 178-179. Sobre el origen estoico de esta idea según la cual es en función del hombre que el mundo existe por la providencia ver E. Thomassen, Le Traité Tripartite, 402, comentario 104, 18-30. 
De la substancia del diablo. Orígenes y la dinámica del sistema valentiniano... 617

(attr.) hermoso ${ }^{43}$, lo cual aproxima, por un lado, la concepción valentiniana del concepto griego de cosmos (cf. LXX Gen. 2, 1), y por otro, muestra claramente la visión positiva que estos autores tienen sobre la creación. Concepción compartida también por Orígenes quien afirma que el universo fue creado para y a causa del hombre ${ }^{44}$.

En el texto valentiniano, la creación del hombre se realiza gracias al Logos y por intermedio del demiurgo. Hay una multitud de entidades que participan de ella:

"La Creación del Hombre (лтсємо ёпршиеє) ocurrió como la de lo demás: el Logos espiritual lo puso invisiblemente en movimiento, pero lo completó por medio del demiurgo y de sus ángeles servidores, al que se han asociado en la plasmación $(\pi \lambda \alpha \dot{\sigma} \sigma \sigma \varepsilon v v)$, el antes mencionado pensamiento con sus arcontes" ${ }^{\$ 5}$.

El Tratado Tripartito resume las diversas creaciones de las almas de la siguiente manera: el Logos espiritual produce, mediante el demiurgo, el alma del primer hombre, por su parte, el demiurgo y entidades del

43 W. E. Crum, A Coptic Dictionary (Oxford, 1962²) 315a y 434a; P. Cherix, Lexique Copte, Copticherix, UniGe (2007) 50a. Planteamos la hipótesis de una relación semántica establecida por al autor gnóstico con el sustantivo $\mathrm{ca}$ que indica "aquel que hace algo", que "fabrica algo". W. E. Crum, A Coptic..., 315a; P. CherIX, Lexique..., 36b.

44 Orígenes, Homélies sur la Genèse I, 12, éd. H. De LubaC - trad. L. Doutreleau (SC 7 bis) (Paris, 1976) 54-55. En el Comentario sobre el Evangelio de Juan, Orígenes afirma la perfección original de la creación y argumenta que la deficiencia del mundo material es el resultado del abandono por parte del hombre, de las realidades superiores. La creación sensible es producto de la caída, ya que el mundo devino material a causa de los hombres que tenían necesidad de vivir en medio de la materia luego de su desobediencia a los mandamientos divinos (Orígenes, In Jo., XIX, XX, 132 (SC 290), 126-127). El universo material es un lugar de aflicción dónde cae Adán, expulsado del paraíso y arrojado en "un mundo hundido en la materia».

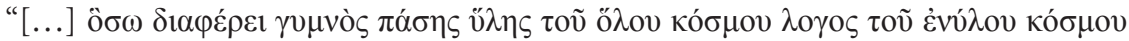
[...]”. OríGENES, In Jo., XIX, XXII, 147 (SC 290), 136-137.

45 TrTrip 104, 30-105, 3. E. Thomassen - L. Painchaud, "Traité Tripartite", EcrGnos, 174-175. E. Thomassen, Le Traité Tripartite (BCNH 19), 178-181. "El pensamiento mencionado más arriba y sus arcontes", se trata del pensamiento presuntuoso del Logos, del cual él se deshizo (90, 18-19) y los arcontes del orden de la imitación o «la izquierda». Este mismo pensamiento presuntuoso es la disposición mental que une el orden de los psíquicos o «la derecha» a la materia, y que permite la interacción de dos órdenes (psíquico y material) con el fin que el mundo sea producido. L. Painchaud - E. Thomassen, “Traité Tripartite”, EcrGnos, 168, nota 98, 27-99, 4 y 174 , nota $104,9-17$. 
orden de la izquierda también producen almas de su propia sustancia. Sin embargo, el texto precisa que: "[...] el creador (льрєссшит i.e. el demiurgo) pensó que ella (i. e. el alma del primer hombre) era suya, puesto que desde él viene, igual que sucede con una cánula a través de la que se sopla" ${ }^{46}$. Sin embargo, la chispa espiritual es siempre una semilla del Logos.

Una de las interpretaciones extraídas por Einar Thomassen de este texto, concierne los tres niveles o tipos del alma humana. Dice el Tratado:

"La sustancia espiritual es un [nombre] (or $[\mathrm{p}] \in \mathrm{N})$ y una sola representación (oresre s̄or dición de [multi]forme. Sin embargo, la constitución de la sustancia de los psíquicos es doble, ya que tiene (el) conocimiento de lo

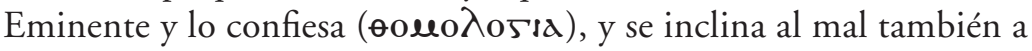
causa de (la) inclinación del pensamiento. ${ }^{47}$ Finalmente, la sustancia material, su tendencia es opuesta y multiforme" ${ }^{38}$.

Thomassen interpreta que el primer hombre consta de dos sustancias, ya que no tiene componente psíquico independiente ( $c f$. TrTrip 105, 22-32); lo material resultante de la unión de las órdenes psíquico y material y el alma espiritual embrionaria aportada por el Logos ${ }^{49}$. De hecho, el texto afirma:

46 TrTrip 105, 32-35. F. GarCía BazÁn, “Tratado Tripartito NHC I 5”, Textos Gnósticos, 194. L. Painchaud - E. Thomassen, “Traité Tripartite”, EcrGnos, 176. L. Painchaud - E. Thomassen, Le Traité Tripartite (BCNH 19), 182-183. Thomassen afirma que el Tratado Tripartito establece una revisión de la doctrina valentiniana original según la cual una semilla espiritual es sembrada por Sofía en el alma del primer hombre producida esta por el demiurgo y no, como lo afirma el Tratado, que el alma del hombre espiritual es una creación del Logos. Sin embargo, es nuestra opinión que en ambos casos el elemento espiritual es siempre una semilla del Logos. La verdadera diferencia se manifiesta por el hecho de que en otros textos como el Libro de los Secretos de Juan el demiurgo consigue robar una partícula de luz perteneciente a Sofía, mientras que aquí el arconte parece no tener ningún contacto, e incluso ningún contacto ningún conocimiento de la existencia, de las realidades superiores.

47 Pensamiento presuntuoso, pasión del Logos que da origen al mundo sensible.

48 TrTrip 106, 6-18. F. García BazÁn, “Tratado Tripartito NHC I 5”, Textos Gnósticos, 194. L. Painchaud - E. Thomassen, E, Le Traité Tripartite (BCNH 19), 182-185. Aceptamos las conjeturas propuestas por Thomassen sobre los términos inciertos. Idem, 406. Voir aussi, L. PAinChaud - E. Thomassen, «Traité Tripartite», EcrGnos, 176. 
"El primer hombre es de hecho una modelación (orm $\lambda$ aceua) y plasmación mixta, y un depósito de los de la izquierda y de los de la derecha, así como de un Logos espiritual, por lo que su propósito se divide (пни) entre cada una de las dos sustancias (алєсте

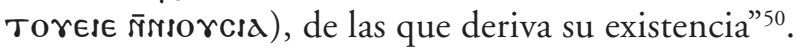

Thomassen explica la omisión del texto respecto de la sustancia espiritual: "Las 'dos sustancias', en realidad, tres sustancias, han sido mencionadas anteriormente; lo que proviene de lo espiritual, sin embargo, no está probablemente incluido aquí; la noción de mezcla, se aplica específicamente a la unión de lo psíquico y lo hílico" ${ }^{51}$.

Por nuestra parte, consideramos que el texto se refiere bien a la sustancia espiritual, ya que la tensión al interior del hombre se produce en un sistema dinámico que comprende las tres sustancias que lo componen: espíritu-alma-materia. Explicitaremos a continuación dicho sistema.

Nuestra hipótesis es confirmada por el Tratado Tripartito, ya que la parte espiritual queda sometida y no tiene el suficiente poder para resistir a las condiciones impuestas por las sustancias psíquicas y materiales: "La nobleza de la sustancia superior que residía (є тсג $\bar{\tau} \bar{\pi} \in \tau$ ууоот) en el hombre era muy alta; sin embargo, participó en la creación (a тcero) sin chocar con ellos" 52 . La sujeción de la parte espiritual es una experiencia ordenada por la economía salvífica. El hombre espiritual se encuentra tensionado entre el espíritu, el alma y el cuerpo por la economía del Padre, pero al final será reunido, cuando los miembros del cuerpo de la Iglesia sean restaurados en el Pleroma ${ }^{53}$.

50 TrTrip 106, 18-25. F. García BazÁn, “Tratado Tripartito NHC I 5”, Textos Gnósticos, 194. L. Painchaud - E. Thomassen, "Traité Tripartite", EcrGnos, 176. L. Painchaud - E. Thomassen, Le Traité Tripartite (BCNH 19), 184-185.

51 L. Painchaud - E. Thomassen, Le Traité Tripartite (BCNH 19), 407.

52 TrTrip 106, 31-35. F. García BazÁn, "Tratado Tripartito NHC I 5", Textos Gnósticos, 195. L. Painchaud - E. Thomassen, “Traité Tripartite”, EcrGnos, 177 y nota 106, 31-34. L. Painchaud - E. Thomassen, Le Traité Tripartite (BCNH 19), 184-185. Ver el comentario de L. Painchaud - E. Thomassen, Le Traité Tripartite (BCNH 19), 407, nota 106, 31-35.

53 TrTrip 106, 31-107, 35 y en un marco más amplio hasta 123, 24. F. GarCía BAZÁn, "Tratado Tripartito NHC I 5", Textos Gnósticos 195 y 205. L. Painchaud - E. Thomassen, "Traité Tripartite», EcrGnos, 192-193. L. Painchaud - E. Thomassen, Le Traité Tripartite (BCNH 19), 222-225. Ver también ApocSant 12, 3-4. 
Entonces, el Logos modela al hombre a través del demiurgo, pero se trata de una forma deficiente (yJa) que no se parece (racersie apaq) al Logos, ya que es producida en un estado de ignorancia, para que el hombre haga la travesía de los padecimientos sensibles y la búsqueda de realidades superiores. En efecto, el primer hombre recibe el espíritu, pero todavía tiene que sufrir las enfermedades traídas por las potencias psíquicas y materiales. Es el estado de la primera forma $(\bar{r} † \underline{\text { p }} \overline{\mathrm{p}}$ еффорен TracTrip 61,2$)^{54}$, que todavía no ha recibido la gnosis, la formación en el conocimiento. El hombre es, en este sentido, semejante al demiurgo. E. Thomassen remarca en las líneas siguientes que hacen

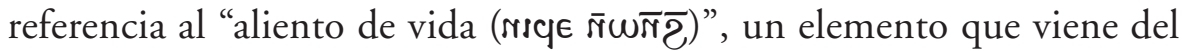
eón invisible, el alma viviente que "da vida a la sustancia que anteriormente estaba muerta". Es el alma "vivificante" que será formada en el conocimiento y que permanece oculta en esta existencia, donde prima la ignorancia. Este "aliento de vida" reinterpreta aquel de Génesis 2, 7 donde el demiurgo (=Dios del Antiguo Testamento), cree que fue él quien lo produjo, pero el autor valentiniano revela que es obra del Logos espiritual ${ }^{55}$. Esta alma-espíritu, todavía en estado seminal ${ }^{56}$, tiene que sufrir el ataque y asedio de las sustancias psíquicas y materiales que también conforman el ser humano ${ }^{57}$.

E. Thomassen ve en otras fuentes valentinianas la implantación de una semilla espiritual, sembrada por Sofía y/o el Salvador, sin el conocimiento del demiurgo y de los ángeles, en el hombre psico-ctónico. Sin embargo, dice el autor:

"La versión del Tratado Tripartito [...] es más elaborada que aquella que encontramos en los testimonios de los Padres de la Iglesia, y ella adopta una perspectiva diferente al afirmar que los elementos provenientes del Logos se encarnan esencialmente con el objeto de desarro-

54 L. Painchaud - E. Thomassen, Le Traité Tripartite (BCNH 19), 296-297.

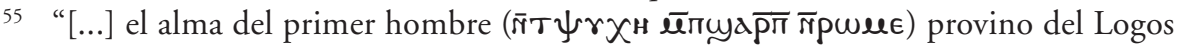

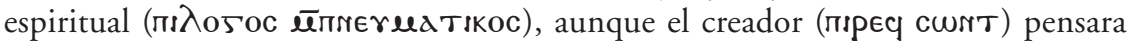
que era suya", ya que ella salió de él. TrTrip 105, 30-35. L. Painchaud - E. Thomassen, Le Traité Tripartite (BCNH 19), 182-183. También, L. Painchaud - E. Thomassen, "Traité Tripartite”, EcrGnos, 175-176, note 102, 7-11.

56 L. Painchaud - E. Thomassen, "Traité Tripartite", EcrGnos, 175-176, note 105, 29-32.

57 TrTrip 106, 35-107, 1. L. Painchaud - E. Thomassen, Le Traité Tripartite (BCNH 19), 182-183. También, L. Painchaud - E. Thomassen, "Traité Tripartite", EcrGnos, 176. Ver Orígenes, In Jo., XIII, XX, 120 y XXV, 149 (SC 222), 94-95 y 112-113. 
llarse e instruirse, el autor hace hincapié en el hecho que ellos deben pasar por las mismas enfermedades que aquellas experimentadas por el Logos en tanto que partes integrantes del mundo del demiurgo, y la descendencia del Logos debe pasar a través de la condición imperfecta de este mundo para llegar al conocimiento de lo que es superior" 58 .

Se dijo en los párrafos anteriores que la doctrina dinámica a la cual se refiere E. Thomassen incluye, en nuestra opinión, las tres sustancias que componen al hombre: espíritu-alma-materia y esta afirmación de Thomassen permite aclarar nuestro propósito. El alma espiritual embrionaria está sometida a los otros dos órdenes (psíquico y material) y esta situación es querida por el Padre para que el hombre haga la experiencia de los sufrimientos que componen el mundo sensible.

Incluso Orígenes parece reconocer en Heracleón una concepción similar donde los espirituales también deben ser salvados. En su refutación al comentario del valentiniano sobre Juan 2, 14, Orígenes afirma: “[...] él (i.e. Heracleón) piensa que es para que no se fuera a imaginar que solo los llamados, privados del Espíritu, reciben la ayuda del Señor"59. Esta afirmación es confirmada por la interpretación, también aportada por Orígenes en In Jo XIII, X-XI, XV, XX, XXV, donde Heracleón expone sobre el diálogo con la Samaritana (Jn 4, 7-25): “[...] y él piensa que aquel a quien el Salvador llama el marido de la Samaritana, es su pleroma $(\pi \lambda \eta ́ \rho \omega \alpha)$, de manera que, viniendo con él junto al Salvador, ella podrá recibir la fuerza, la unión, la intimidad con su pleroma [...]"60. Aquí la Samaritana representa, la semilla espiritual, prisionera del cosmos arcóntico, ella debe recibir entonces la gnosis de parte de su marido $^{61}$, ya que, dice Heracleón, y cito "no conocía a su propio marido, en sentido espiritual, sino en sentido más simple, ella se avergonzaba de confesar que tenía un amante y no un marido [...]"62.

58 L. Painchaud - E. Thomassen, Le Traité Tripartite (BCNH 19), 404.

59 Orígenes, In Jo X, XXXIII, 211, ed. C. BlanC (SC 157), Paris, 1970, 510-511, ver nota 1 .

60 Orígenes, In Jo XIII, XI, 67 (SC 222), 66-67. Sobre los diferentes niveles de interpretación ver T. J. PetTipiece, Heracleon..., 26 y principalmente 86.

61 Esta interpretación, sobre una contradicción aparente en las afirmaciones de Hercleón donde la samaritana "espiritual" debe ser salvada ya que ha sido prostituida, es también enunciada por Orígenes en OríGENES, In Jo XIII, XI, 73-74 (SC 222), 70-71

62 Orígenes, In Jo XIII, XI, 69 (SC 222), 66-69. El tema de la necesidad de la salvación de la mujer "espiritual" se continúa en In Jo XIII, XV, 92 (SC 222), 78-81. La metáfora de la mujer prostituida por sus amantes, recuerda aquella presentada por 
Por lo tanto, el demiurgo y las potencias psíquicas y materiales colaboran en la formación del alma humana, aportando cada una, una parte que se le asemeja ${ }^{63}$. Como resultado, la creación del hombre sigue el mismo orden jerárquico que define la fidelidad de las emanaciones y que las sitúa según los tres niveles: el orden espiritual, o el de las imágenes

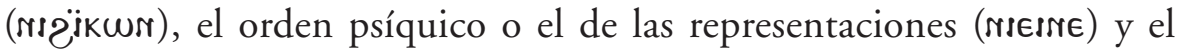

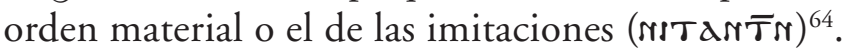

Los dos términos coptos esre y Tarī̄r reenvían al griego ỏ $\mu$ oí $\omega \sigma \varsigma^{65}$ que tiene para los exégetas bíblicos un valor más cercano al modelo. De hecho, para los Padres la similitud es más cercana a la figura del creador, ya que representa a Cristo ${ }^{66}$. Filón (Opif. 71), también cree que la "representación" aumenta la fidelidad de la "imagen" porque la imagen

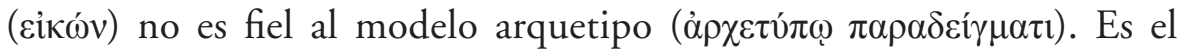
término "representación" que especifica la precisión relativa al modelo.

El autor gnóstico del Tratado Tripartito propone, para la exégesis de Génesis 1, 26, una interpretación que considera la imagen como la más fiel al modelo. En efecto, el hombre no solo es la causa de la creación del universo, porque todo fue hecho por él, sino que incluso contiene en sí mismo un microcosmos a la imagen del macrocosmos ${ }^{67}$. Ha sido

el texto de Nag Hammadi, llamado «La Exégesis del Alma» NH II, 6. Ver también, T. J. Pettipiece, Heracleon..., 86 y principalmente 88.

63 "El creador también envió hacia abajo almas salidas de su propia sustancia (тeqorcı), puesto que también él tiene poder para engendrar, porque es una existencia derivada de la representación del Padre. También produjeron los de la izquierda hombres a la manera propia, puesto que tienen la imitación (ёлталтйє) de <...>”. TracTri 105, 35-106, 5. F. García BazÁn 194. E. Thomassen, Le Traité Tripartite (BCNH 19), 184-185. Aussi, L. Painchaud - E. Thomassen, "Traité Tripartite", EcrGnos, 177.

64 "Pues la preparación completa de la disposición de las imágenes (rıð̈ikwr), repre-

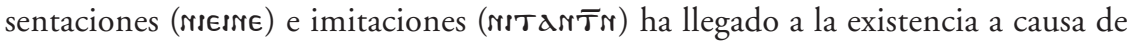
los que necesitan instrucción, enseñanza y formación (rsor careuy uñrs orchw

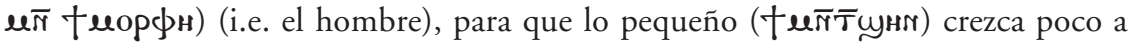
poco", TracTri 104, 18-31. F. García BazÁn, "Tratado Tripartito NHC I 5", Textos Gnósticos, 193. L. Painchaud - E. Thomassen, Le Traité Tripartite (BCNH 19), 178-179. Sobre la organización del cosmos ver F. GarCía BAZÁn, "Tratado Tripartito NHC I 5", Textos Gnósticos, 143.

65 W. E. Crum, A Coptic..., 80 b y 420 b; P. Cherix, Lexique..., 11 b y 48 b.

66 Irénéo de Lion, Adversus haereses V , 16, 1-2; Clément D'AleXAndrie, Stromata II , XXII, 131, 5-6; OrigÈne Peri Archôn, III, 6, 1.

67 Ver F. García BazÁn, “Tratado Tripartito NHC I 5”, Textos Gnósticos, 145. 
compuesto por los tres órdenes que componen el universo (imágenes, representaciones e imitaciones); y que se consideran reflejos de realidades superiores. Cada uno de estos órdenes ha sido producido por el Logos en un momento diferente de su división y de su redención. De la emisión inferior del Logos proviene el orden de la imitación, las sombras y semejanzas $(78,29-36)$. Del recuerdo de las realidades superiores, el Logos emitió el orden del recuerdo o las representaciones. Entonces, de la manifestación del Salvador y de la formación espiritual del Logos, proviene el orden espiritual, "a imagen del pleroma (

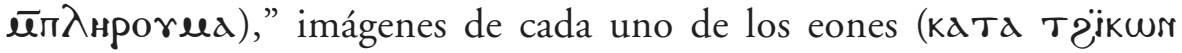

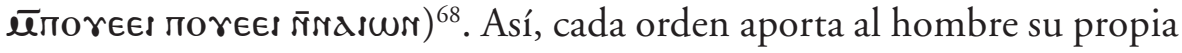
sustancia: falsificación material para el orden de la izquierda o imitaciones, representación psíquica para el orden de la derecha e imagen espiritual de parte de las imágenes de los eones.

En consecuencia, podemos leer en el texto: "La humanidad llegó a

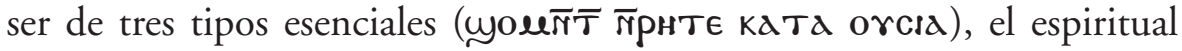

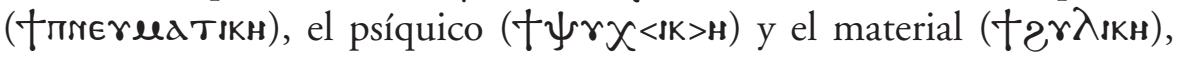
reproduciendo el modelo (тилос) de la triple disposición del Logos, por la que, sin embargo, se produjeron los materiales, los psíquicos y los espirituales" ${ }^{\prime 69}$. El sistema dinámico consiste en la instrucción gnóstica para desligar la semilla luminosa de su sometimiento. Dicho sistema, existe desde la creación del hombre, pero es la venida del Salvador quien trae al cosmos el conocimiento de su jerarquización: "Cada una de las esen-

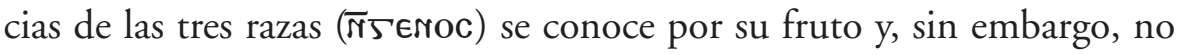
fueron conocidas de entrada, sino solo con la venida del Salvador (пблєड етпсштнр), que iluminó a los santos y reveló que cada uno era”70.

\section{Los Extractos de Teódoto}

Expondremos en este último tramo las precisiones aportadas por un texto perteneciente a otro de los seguidores de Valentín. Los Extractos

68 TrTrip 94, 10-12 et 34-35. F. García BAZÁN, “Tratado Tripartito NHC I 5”, Textos Gnósticos, 186. L. Painchaud - E. Thomassen, Le Traité Tripartite (BCNH 19), 154155. También, L. Painchaud - E. Thomassen, “Traité Tripartite”, EcrGnos, 164.

69 TrTrip 118, 14-21. L. Painchaud - E. Thomassen, Le Traité Tripartite (BCNH 19), 212-213. También, L. Painchaud - E. Thomassen, “Traité Tripartite”, EcrGnos, 188.

70 TracTri 118, 21-28. F. GarCía BaZÁn, "Tratado Tripartito NHC I 5”, Textos Gnósticos, 202. L. Painchaud - E. Thomassen, Le Traité Tripartite (BCNH 19), 214-215. También, L. Painchaud - E. Thomassen, “Traité Tripartite”, EcrGnos, 188. 
de Teódoto, son escritos de un maestro valentiniano transmitidos por Clemente de Alejandría hacia fines del siglo II y principios del siglo III. El Extracto 51 explicita la división dinámica valentiniana del hom-

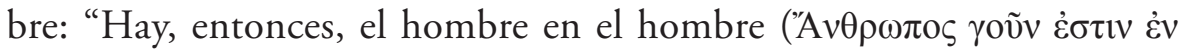

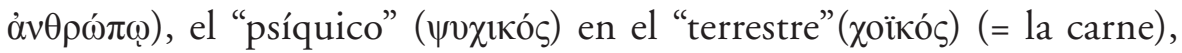
no como una parte que se agrega a una parte, pero como un todo uniéndose a un todo. [...] para el alma "divina" [= psíquica] el alma "material"

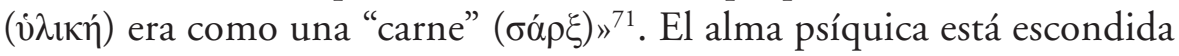
dentro del alma material, que es el cuerpo de la primera. Es de esta alma material de la cual hay que deshacerse. Los tres elementos están íntimamente relacionados, y en un tercer nivel: "Adán poseía, plantado

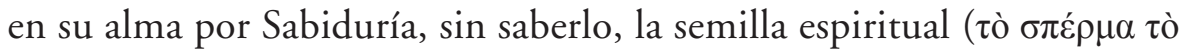
$\pi v \varepsilon v \mu \alpha \tau$ «óv). Por lo tanto, Sabiduría emitió la semilla espiritual que es la médula de los huesos representados por el alma psíquica y el hombre es movido secretamente por ella, como el demiurgo es impulsado en secreto por la Sabiduría"72.

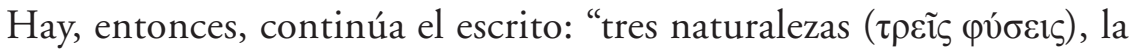

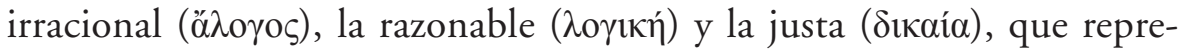
sentan «el hombre terrestre que es " a la imagen”; el psíquico "a la semejanza “ de Dios y el "espiritual” que es "en sí mismo”( $\alpha \tau$ i ííav). Sobre

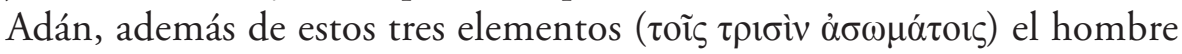
es revestido con "túnicas de piel"73.

Sin embargo, en los Extractos de Teódoto, el concepto de "imagen" es el de un producto inferior resultante de la ruptura de la pareja pleromática: "Así, mientras la unidad existe en el Pleroma, cada uno de los eones

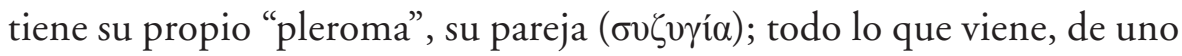

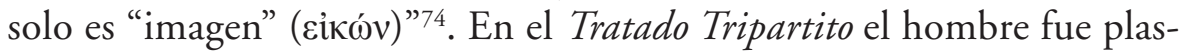
mado por el Logos convertido pero todavía no redento, y por lo tanto el concepto de imagen presente en los Extractos es también aplicable al tratado de Nag Hammadi. Así, en la frase siguiente los Extractos vuelven sobre el sentido positivo de la imagen: "Esta es la razón por la cual Teódoto llama a Cristo, que proviene de la idea (Ěvvora) de la Sabiduría,

71 F. Sagnard (éd.) Clémente de Alejandria, Extr. Teod. 51, 1-2 (SC 23), éd. (SC 23) (París, 1970) 164-165. Ver también ApocrJn NH II , 18, 34.

72 Clémente de Alejandria, Extr. Teod. 53, 2-5 (SC 23), 168-169.

73 Clémente de Alejandria, Extr. Teod. 54, 1-55, 1 (SC 23), 170-171.

74 Clémente de Alejandria, Extr. Teod. 32, 1 (SC 23), 128-129. 


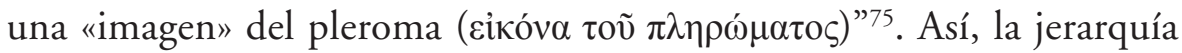
valentiniana del Tratado Tripartito no es modificada sino enriquecida

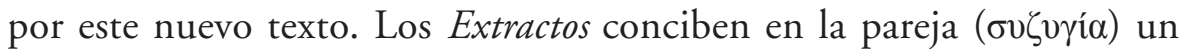
nivel superior, más perfecto, el producto completo contrario a la "imagen”, que vale solo en relación con el prototipo de quien ella es como un reflejo. Es la semilla espiritual despertada de su letargo por la gnosis aportada por su cónyugue.

Por otra parte y volviendo al Tratado Tripartito, la aceptación valentiniana del cuerpo como un elemento material que contribuye también a la economía salvadora, se manifiesta a propósito del cuerpo del Salvador. El Salvador se encarnó para aquellos a quienes vino a salvar, aquellos que

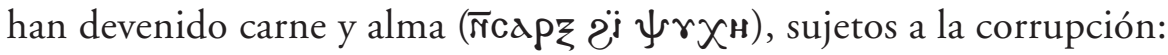

"No solo él (i.e. el Salvador) asumió por ellos la muerte de los que pensó salvar, sino que tam[bién] su pequeñez (иятиунщ), a la que han descendido cuando nacieron en cuerpo y alma (псшещd T $\Psi \gamma\left({ }^{H}\right)$, la asu[mió] igualmente para esto, porque permitió ser concebido y engendrado como un infante en cuerpo y alma"76.

Esta idea se refleja también en los Extractos de Teódoto 31 y 31 donde el

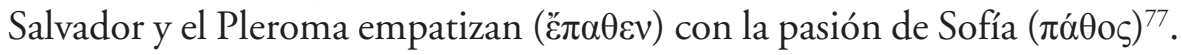

\section{CONCLUSIÓN}

En la primera parte de nuestro trabajo hemos expuesto la posición de Orígenes y sus críticas a las ideas valentinianas sobre la concepción del hombre y su salvación. Para el alejandrino, Dios busca solamente el bien del hombre, pero el hombre dotado de libre albedrío puede reaccionar favorablemente o no a la iniciativa divina, haciendo el bien o el mal. No existe imposición alguna sobre el destino humano y esta afirmación gnóstica indigna al Padre de la Iglesia.

75 Extr. Teod. 32, 2. Extr. Teod., 130-131.

76 TrTrip 115, 4-11. F. García BazÁn, “Tratado Tripartito NHC I 5”, Textos Gnósticos, 200. L. Painchaud - E. Thomassen, Le Traité Tripartite (BCNH 19), 204-205. También, L. Painchaud - E. Thomassen, “Traité Tripartite”, EcrGnos, 184-185. Sin embargo, el cuerpo que encierra el alma no será resucitado al fin de los tiempos. La carne no heredará el reino de Dios nos dice el Evangelio de Felipe (EvFlp. 56, 26-34). Cf. I Co 15, 50.

77 Ver el artículo de J. D. Dubois, "La Sotériologie valentinienne du Traité Tripartite (NH I, 5)", 221-232. 
Nuestro análisis de los textos valentinianos intenta describir la complejidad del sistema que no se resume a una división entre tres naturalezas inmutables predestinadas a la condena o la salvación. La mezcla y la tensión consecuente, expuestas por E. Thomassen en su afirmación sobre "las dos sustancias", se manifiesta claramente en el Tratado Tripartito: los dos órdenes (derecha e izquierda, psíquicos y materiales)

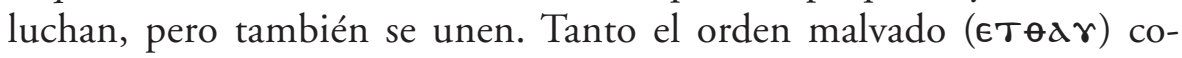

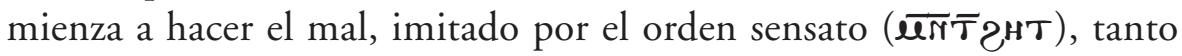
este último hace el bien para ser imitado por el primero ${ }^{78}$. De manera tal que estas dos naturalezas se encuentran íntimamente relacionadas. Dicha relación, tal cual lo expone el Tratado Tripartito y lo explicitan los Extractos de Teódoto, se reproduce al interior del hombre e implica una cierta influencia sobre el elemento espiritual. Sin embargo, y esto es un punto esencial para entender el sistema dinámico valentiniano, la tensión que esta triple relación conlleva es necesaria a la economía salvífica establecida por el Padre.

Por lo tanto, aceptamos la afirmación de Francisco García Bazán: "Hay tres tipos de hombres y el gnóstico los comprende a los tres"79, pero la ampliamos al preguntarnos si el sistema valentiniano presenta la posibilidad de que la conversión hacia la gnosis sea asequible a todos los hombres según su compromiso con la revelación salvífica ${ }^{80}$. O como afirma Jean-Daniel Dubois: "entre los gnósticos valentinianos, el sufrimiento del Salvador sobre la cruz sirve de explicación del sufrimiento humano en general; y más precisamente, la pasión del Salvador es una metáfora del combate gnóstico contra la deficiencia y las pasiones de la condición humana" ${ }^{1}$.

Repensamos entonces la interpretación de Einar Thomasen quien en su lectura de TraTrip 109, 24-112, 9 afirma:

"Los griegos y los bárbaros son pueblos materiales, cuya ciencia y filosofía no van más allá de su propia esfera. Los cristianos no valentinianos y los judíos, progenie del demiurgo, tienen un grado más

78 TracTri 108, 23-35. F. GarCía BAZÁn, “Tratado Tripartito NHC I 5”, Textos Gnósticos, 196. L. Painchaud - E. Thomassen, Le Traité Tripartite (BCNH 19), 188-191. También, L. Painchaud - E. Thomassen, "Traité Tripartite”, EcrGnos, 179.

79 F. García BazÁn, “Tratado Tripartito NHC I 5”, Textos Gnósticos, 145.

80 Ver F. García BazÁn, La Gnosis Eterna I, Madrid-Barcelona, 2003, 13.

81 J. D. Dubois, Jésus Apocryphe, Paris, 2011, 103. Ver TrTrip 119, 24-27. L. PainChaud - E. Thomassen, "Traité Tripartite", EcrGnos, 189, nota 119, 24-27. 
De la substancia del diablo. Orígenes y la dinámica del sistema valentiniano... 627

elevado de conocimiento religioso, pero este está contaminado por el materialismo griego. [...] La tercera clase está formada por todos aquellos que han recibido la semilla espiritual con la cual se identifican los valentinianos mismos" $\$ 2$.

En otras palabras, debemos preguntarnos dónde ubicarían los autores gnósticos valentinianos el llamado de Pablo a la conversión de los gentiles (Hch 16, 32, 17, 22-34 Cf. Gal. 4, 10, 6, 12) ${ }^{83}$.

$Y$ en este sentido se plantea la interpretación del fragmento de Heracleón presente en In Jo XIII, XXXVIII, 248: "Él decía (i.e. Heracleón) que la voluntad del Padre es que los hombres conozcan al Padre y sean salvados, lo cual era la obra propia del Salvador, enviado con este obje-

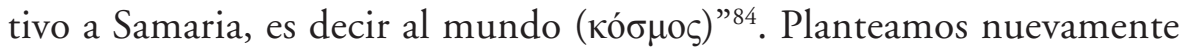
la pregunta en palabras de Timothy Pettipiece refiriéndose al mismo fragmento del maestro valentiniano:

"Esto parece indicar una posición teológica más inclusiva tomada por Heracleón, ya que él no dice que la voluntad del Padre es que solo los seres humanos pneumáticos deben ser salvados, sino que simplemente los seres humanos en general debe ser salvados. Esta es, sin embargo, una citación aislada; basados en otra evidencia (como el fragmento 46), parece claro que existen al menos algunos individuos a quienes Heracleón considera más allá de la salvación” ${ }^{” 5}$.

82 L. Painchaud - E. Thomassen “Traité Tripartite”, EcrGnos, 114. Cf. lo afirmado por Heracleón en In Jo XIII, XVI, 95-96 (SC 222), 80-83.

83 En referencia a los psíquicos, entre los cuales Heracleón parece considerar a los judíos, leemos una interpretación del Alejandrino sobre el comentario del valentiniano de Jn 4, 23 referido por Orígenes en In Jo XIII, XIX, 115. "Él explica que, en sentido espiritual, la salvación viene de los Judíos, porque ellos son considerados como imágenes de aquellos que están al interior mismo del pléroma". "Il explique que, au sens spirituel, le salut vient des Juifs, parce qu'ils sont considérés comme des images de ceux qui sont à l'intérieur même du plérôme”. In Jo XIII, XIX, 115 (SC 222) 92-93. Orígenes, In Jo XIII, XXXVIII, 248 (SC 222), 162-165 y Cf. con nota 5, 163-164.

85 «This seems to indicate a more inclusive theological position taken by Heracleon, since he does not say that the will of the Father is that only "pneumatic» human beings should be saved, but simply that human beings in general should be saved. This, however, is only an isolated citation; based on other evidence (such as Fragment 46), it seems clear that there are at least some individuals whom Heracleon considers beyond redemption». T. J. Pettipiece, Heracleon..., 115. Un poco mas adelante Pettipiece afirma con respecto al fragmento de In Jo XIII, XLIV, 294: "In other words, those that are "fit» to be harvested are those individuals who recongnize their "pneumatic» nature". Heracleon..., 119. Ver también Heracleon..., 124. 
De esta forma, tal cual señalamos, el elemento material participa también de la dinámica de la salvación, es en este sentido que el cuerpo físico es la prisión del alma. Él implica el ataque de las pasiones y las sensaciones sobre el espíritu y el alma, él representa el riesgo de apartarse del objetivo salvador y el olvido de los orígenes ${ }^{86}$.

Es así como no hay determinismo en el sistema valentiniano, tal cual lo expone claramente el Tratado Tripartito y cito expresamente el texto: "es por el fruto (пєскарпос) que se reconoce la esencia de cada una

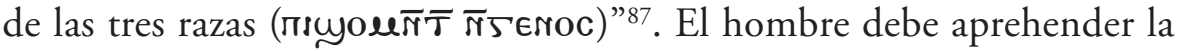
revelación aportada por el Salvador para liberarse de las cadenas arcónticas, ya que nos es la naturaleza del hombre la que legitima el comportamiento, sino el comportamiento el que revela la naturaleza $(\operatorname{Tr} \operatorname{Tr} i p 118$, $24-119,21)^{88}$.

${ }^{86}$ Afirmación paralela a la concepción plotiniana del cuerpo tal cual es descripta por Pierre Hadot: Plotino no rechaza el cuerpo en sí, sino las cosas sensibles que impiden prestar atención a la vida espiritual. P. НADOT, Plotin ou la simplicité du regard, Paris, Gallimard, 1997, 37. Es así como el cuerpo representa una imagen ligada a la muerte, la muerte espiritual. Ver también lo expuesto por Elaine Pagels en E. Pagels, The Johannine Gospel in Gnostic (Nashville \& New York, 1973) 99-104.

87 TrTrip 118, 21-23. F. GarCía BAZÁn, "Tratado Tripartito NHC I 5", Textos Gnósticos, 202. L. Painchaud - E. Thomassen, Le Traité Tripartite (BCNH 19), 212-213. También, L. Painchaud - E. Thomassen, "Traité Tripartite", EcrGnos, 188.

88 Resulta interesante detenerse en los términos utilizados por Heracleón para definir a los hombres que pertenecen al mundo material tal cual han sido recogidos por Pettipiece: "At the other end of the spectrum in Heracleon's classification of human beings are those who are immersed in the «lower regions of the world» ( $\tau \dot{\alpha}$ है $\sigma \chi \alpha \tau \alpha$

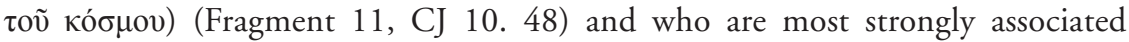

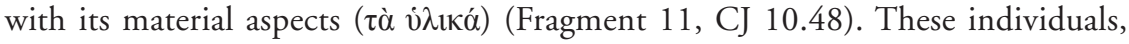

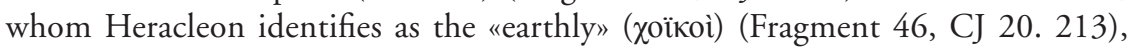

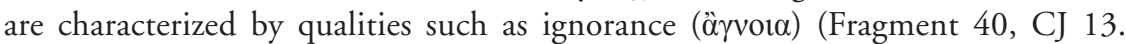

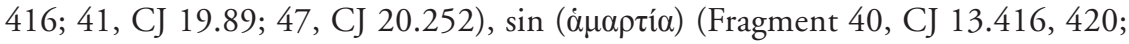

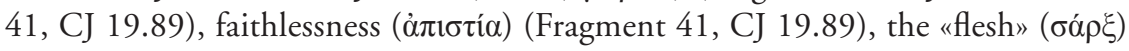
(Fragment 8, CJ 6.198; 22, CJ 13.117; 24, CJ 13.148; 30, CJ 13.226), and are even

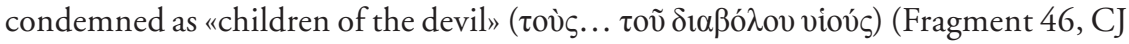
20.213). In an intereseing early use of the term, this class of individuals is described

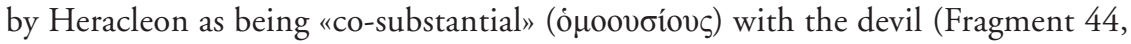
CJ 20.170), and is related to him «nature» (Fragment 46, CJ 20.213). As such, Heracleon is clear that these individuals are of «adifferent substance than those who are called psychics or pneumatics» (Fragments 44, CJ 20.170)". T. J. PetTipiece, Heracleon..., 163-164. Remarcamos por nuestra parte como la mayor parte de los términos usados tienen un carácter ético. En palabras de Michael Williams, «If it should be true that some writers and readers of these demiurgical texts did think 
De la substancia del diablo. Orígenes y la dinámica del sistema valentiniano... 629

Los espirituales reconocen al Salvador, aceptan la gnosis y reciben una salvación completa. Mientras que los materiales son «extraños (yещещo) bajo todo aspecto» ${ }^{89}$, refractarios a la instrucción y recibirán la destrucción absoluta. Sin embargo, dichas categorías se manifiestan una vez que la gnosis ha sido revelada y su interiorización aceptada o rechazada por los individuos.

Por su parte, los psíquicos dudan en aceptar el conocimiento dado que «su constitución es doble de acuerdo con su disposición tanto para el bien como para el mal $»^{90}$. Sin embargo, una vez aceptada la gnosis dice el texto: «Se salvarán totalmente [a causa] del pensamiento salvífico (пљеє sistema $^{92}$, dinámica que implica e incluye al elemento espiritual pero también al elemento material.

of themselves as belonging to a "spiritual» elite destined for salvation, there still is little evidence that such people as a result tended to consider ethics to be irrelevant. As the study of various predestinarian religious traditions shows, where proper behaviour is understood to be the very sign of membership in the group destined for salvation, such behaviour can be all the more indispensable and therefore and ethical ideal providing an all-consuming motivation"; "Si es verdad que algunos escritores y lectores de estos textos demiúrgicos pensaban en sí mismos como perteneciendo a una élite «espritual» destinada a la salvación, existe todavía poca evidencia que como resultado de ellos tales personas tendían a considerar la ética como irrelevante. Como el estudio de varias tradiciones religiosas predestinatarias muestra, el buen comportamiento es entendido como un signo importante de membresía al grupo destinado a la salvación, tal comportamiento puede ser de lo más indispensable y por lo tanto un ideal ético proporciona una motivación esencial”. M. Williams, Rethinking “Gnosticism»., New Jersey, 1996, 193.

$89 \operatorname{Tr} \operatorname{Tr} i p$ 119, 10. F. GaRCÍA BAZÁN, "Tratado Tripartito NHC I 5", Textos Gnósticos, 202 y nota 87.

90 TrTrip 119, 22-23. F. García BazÁn, “Tratado Tripartito NHC I 5”, Textos Gnósti$\cos , 202$

91 TrTrip 119, 32. F. GarCía BaZÁn, “Tratado Tripartito NHC I 5”, Textos Gnósticos, 202.

92 Ver Irénéo de Lion, Adversus haereses I, 6, 1. 
